\title{
ZUR KRITIK DER GEWALT DE BENJAMIN: CRÍTICA DA VIOLÊNCIA E DO PODER
}

Karla Pinhel Ribeiro

\section{RESUMO}

Em Crítica da Violência, Walter Benjamin apresenta um estudo sobre a tarefa de uma crítica da violência e do poder. Segundo Benjamin, tal crítica permite uma representação das condições do direito e da justiça. Essa esfera de condições designa, por sua vez, as possibilidades de se conceituar o direito e a justiça. Este artigo é uma tentativa de reconstrução do texto Critica da Violência de Benjamin e das análises que foram feitas desse texto por Jaques Derrida e Giorgio Agamben.

Palavras-chaves: Violência. Direito. Poder. Justiça. Walter Benjamin.

\section{ZUR KRITIK DER GEWALT DE BENJAMIN: CRITICISM OF VIOLENCE AND POWER}

\begin{abstract}
In Critique of Violence, Walter Benjamin presents a study about the task of a critique of violence and power. According to him, such criticism allows a representation of the conditions of law and justice. This sphere of conditions then designates the possibilities for conceptualizing law and justice. This paper is an attempt to reconstruct Benjamin's text Critique of Violence and the following analysis that were made by Jacques Derrida e Giorgio Agamben.
\end{abstract}

Keywords: Violence. Law. Power. Justice. Walter Benjamin. 
"Offen bliebe immer noch die Frage, ob Gewalt überhaupt, als Prinzip, selbst als Mittel zu gerechten Zwecken sittlich sei".

Walter Benjamin, Zur Kritik der Gewalt

\section{Introdução}

Walter Benjamin, em Crítica da Violência, apresenta um estudo sobre a tarefa de uma crítica da violência e do poder. Segundo Benjamin, tal crítica permite uma representação das condições do direito e da justiça. Assim, num sentido pragmático e sucinto da palavra, demonstra um caráter sempre de eficácia e de causas para depois intervir. Essa esfera de condições designa então as possibilidades de se conceituar 0 direito e a justiça. $\mathrm{O}$ artigo procura abordar a tese de Benjamin sobre a violência do direito e sua recepção internacional e brasileira.

Nosso objetivo geral na leitura do ensaio benjaminiano sobre a Crítica da Violência é pensar uma filosofia do direito, especialmente a partir do direito natural e do direito positivo, seus aspectos moderno e contemporâneo. Nossa principal abordagem do ensaio é sobre a relação da violência com o direito e com a justiça e o significado do poder. E logo no início do ensaio, Walter Benjamin considera o fenômeno crítico da violência ${ }^{1}$ como sendo a causa eficiente das relações morais entre direito e justiça. $E$ sobre essa relação crítica $^{2}$ na esfera do conceito de direito, o ensaio benjaminiano parte da relação de fim e meio, a relação, para Benjamin, fundamental e mais elementar de todo ordenamento jurídico.

No ensaio, Walter Benjamin ao questionar-se duplamente se "a violência constitui um meio para fins justos ou injustos?" ou ainda se "a violência em geral, como princípio,

1 Gewalt é um conceito polissêmico que significa ao mesmo tempo: poder, força e violência. Hannah Arendt observou em sua obra On violence que apesar de uma mesma palavra ser utilizada em língua alemã, há uma diferença entre poder, força e violência que não é apenas semântica ou gramatical, mas consiste em uma diferença histórica e de natureza.

2 O sentido de crítica para Benjamin consiste em tal como apresentado por ele em Gesammelte Scriften (GS), "crítica pode ser compreendida como uma falta de amor".

Pós-Doutoranda em Filosofia pela Universidade Federal de Santa Catarina, Doutora em Filosofia pela Universidade de São Paulo, Professora de Filosofia e Ciência Politica no Centro Universitário Curitiba, PR. Brasileira, residente em Curitiba-PR. Email: karlapinhelribeiro@gmail.com 
é moral ainda que seja um meio para fins justos?" encontra assim que há uma distinção filosófica na esfera dos meios e dos fins, e este é seu fundamento crítico sobre as doutrinas do jusnaturalismo e do juspositivismo.

Sobre o fundamento crítico do jusnaturalismo, concepção filosófica que, segundo Benjamin, serviu de base ideológica para o terrorismo da Revolução Francesa, a violência é um produto natural, uma matéria prima, cujo emprego não fundamenta problemas, desde que não posta a serviço de fins injustos. Para Benjamin, segundo a teoria jusnaturalista do estado, as pessoas se despojam de toda a sua autoridade em favor do estado, um contrato racional de poder de fato e direito sobre o indivíduo. $\mathrm{Na}$ história da filosofia do direito dogmático, a tese jusnaturalista consiste que a violência para fins naturais é juridicamente legítima, dado que "a violência é um dado natural" e assim "julga o direito existente somente mediante a crítica de seus fins."

Segundo Benjamin, a teoria do juspositivismo compreende-se como poder de transformação histórica e assim "julga todo o direito em transformação somente mediante a crítica de seus meios."

É importante ressaltar que Benjamin não prescinde da oposição entre naturalismo e positivismo e encontra nas duas escolas um dogma fundamental comum: "Os fins justos podem ser alcançados por meios legítimos, os meios legítimos podem ser empregados a serviço de fins justos." Assim, para Benjamin o direito natural "justifica os meios legítimos com a justiça dos fins" e o direito positivo "garante a justiça dos fins com a legitimidade dos meios." A solução da antinomia proposta por Benjamin "parte da compreensão do estabelecimento de critérios independentes para os fins justos e meios legítimos."

A investigação do ensaio de Benjamin torna-se assim uma investigação sobre o reino dos fins e o problema de um critério de justiça e sobre o reino dos meios, o problema da legitimidade/legalidade, com perguntas tais como, por exemplo: "Qual a legitimidade dos meios que constituem a violência?"

Pós-Doutoranda em Filosofia pela Universidade Federal de Santa Catarina, Doutora em Filosofia pela Universidade de São Paulo, Professora de Filosofia e Ciência Politica no Centro Universitário Curitiba, PR. Brasileira, residente em Curitiba-PR. Email: karlapinhelribeiro@gmail.com 


\section{Antinomia benjaminiana}

Para responder às questões propostas para solução da antinomia, Benjamin investiga o fundamento crítico da história das doutrinas do direito natural e do direito positivo à luz de uma filosofia da história.

Sobre a doutrina do direito natural, para Benjamin, "os princípios jusnaturalistas não podem decidir o problema da antinomia, mas somente podem levá-lo a uma casuística sem fim", pois o direito natural é "cego para o condicionamento dos meios."

E mais adiante, sobre a doutrina do direito positivo, Benjamin assinala que "a teoria positiva do direito" é a "hipótese de partida ao começo da investigação" porque o direito positivo "estabelece uma distinção de princípio entre os diversos gêneros de violência, independentemente dos casos de sua aplicação."

Segundo Benjamin, na teoria do direito positivo há uma distinção entre a violência historicamente reconhecida, a violência sancionada como poder, e a violência não sancionada como poder. As análises de Benjamin sobre a crítica da violência, partem desta distinção, todavia Benjamin mesmo assinala que "não significa que os poderes sejam ordenados e valorados de acordo com o fato de que estão sancionados ou não."

Aqui podemos dizer que o ensaio benjaminiano contempla três momentos fundamentais. No primeiro momento do ensaio, Benjamin propõe uma filosofia da história do direito e da justiça para uma crítica da violência, do ensaio questiona o dogma fundamental comum das doutrinas do direito natural e do direito positivo - a violência como fundamento crítico da distinção entre fins e meios. É sobre este primeiro momento do ensaio que tratamos até agora na Seção. O segundo momento, que tratamos a seguir, é o momento em que Benjamin mais especificamente mesmo trata da questão sobre a crítica da violência. O terceiro momento, que tratamos ao final da Seção, é o momento em que Benjamin precisamente trata da questão sobre a vida nua na origem do dogma da sacralidade da vida.

Pós-Doutoranda em Filosofia pela Universidade Federal de Santa Catarina, Doutora em Filosofia pela Universidade de São Paulo, Professora de Filosofia e Ciência Politica no Centro Universitário Curitiba, PR. Brasileira, residente em Curitiba-PR. Email: karlapinhelribeiro@gmail.com 
Ao se perguntar o que é uma crítica da violência, Benjamin responde que se trata "não de simples aplicação do critério do direito positivo", mas trata-se de "julgar a sua vez ao próprio direito positivo."

Uma crítica da violência, segundo Benjamin, é "de ver que consequências e para a essência mesma da violência, o fato mesmo de que seja possível estabelecer a respeito dela tal critério ou diferença." Para uma crítica da violência, "que consequências têm o significado dessa distinção?"

Sobre o direito positivo, a distinção da legitimidade da violência segundo a análise de seu significado, para Benjamin, mostrou ser fundada em si.

Uma crítica da violência, para Benjamin, consiste em "encontrar um critério fora da filosofia positiva do direito e também fora do direito natural." Assim, para Benjamin, o critério da Crítica da Violência consiste em "considerar o direito desde o ponto de vista da filosofia da história."

$\mathrm{Na}$ filosofia da história do direito natural e do direito positivo de Benjamin, o significado da distinção sobre a violência em legítima e ilegítima, no direito natural, consiste na distinção entre "violência com fins justos ou injustos." No direito positivo, o significado da distinção "exige a todo poder uma origem histórica", estabelecendo assim uma relação de historicidade entre sanção e legitimidade, relação de historicidade do poder jurídico como princípio universal de submissão passiva aos seus fins e está ligada ao critério de reconhecimento histórico de seus fins. No direito natural, a relação estabelecida consiste em fins jurídicos e fins naturais.

O conceito de pessoa como sujeito jurídico passível das relações jurídicas em nosso tempo, tornou-se, tal como na filosofia da história do direito natural, alvo de fins naturais e fins jurídicos.

O direito, para Benjamin, é o monopólio da violência para salvaguardar o próprio direito. Benjamin então procura uma violência fora do direito e encontra "a violência atual que o direito trata de proibir."

No ensaio benjaminiano, a função da violência é exemplificada no direito de greve, e para Benjamin, "a classe trabalhadora é hoje em dia, junto com os estados, o único sujeito que tem direito de violência."

Pós-Doutoranda em Filosofia pela Universidade Federal de Santa Catarina, Doutora em Filosofia pela Universidade de São Paulo, Professora de Filosofia e Ciência Politica no Centro Universitário Curitiba, PR. Brasileira, residente em Curitiba-PR. Email: karlapinhelribeiro@gmail.com 
Para Benjamin, a greve é a omissão de uma ação e a ruptura de uma relação, "um meio de todo puro e livre."

A investigação de Benjamin sobre a função da violência, a função da violência que o estado teme, consiste assim no estudo proposto preciso de determiná-la como "único fundamento seguro para sua crítica."

Para Benjamin, em seu ensaio, são sujeitos jurídicos que sancionam poderes cujos fins contemplam, como no caso do direito público: a celebração da paz. No direito público, a violência bélica tem status originário e prototípico. No direito público, a violência é a "existência de um caráter de criação jurídica."

$\mathrm{Na}$ filosofia da história do direito moderno, a pessoa isolada enquanto sujeito jurídico é proibido a violência.

Em sua investigação sobre a função da violência na filosofia da história do direito natural e do direito positivo, crítica de todo poder jurídico legal e executivo e de todo significado moral de atuar, Benjamin em seu ensaio contempla uma dupla função da violência: "criadora de direito" e "conservadora de direito".

Em sua filosofia da história do direito positivo, Benjamin analisa o destino e a crítica origem do direito, que para Benjamin, é a "violência suprema do poder sobre a vida e a morte do ordenamento jurídico". A crítica de Benjamin é que o exercício do poder de vida e morte, a polícia, (deve) ser um ato jurídico, um direito, como no problema da decisão enquanto categoria metafísica na monarquia absoluta, enquanto relação de poder do soberano e polícia e relação de democracia e polícia. Assim, para Benjamin, "toda violência é, como meio, poder que funda ou conserva o direito."

À pergunta de Benjamin sobre a possibilidade de existência de outros meios que não sejam os violentos para harmonizar interesses humanos em conflito segue sua uma crítica da problematicidade do direito em geral, e propõe a paz: a forma pacífica como um meio puro e não violento.

A problematicidade de todo poder jurídico na filosofia da história do direito em geral, a crítica das teorias jurídicas do direito natural e do direito positivo e a crítica a seu dogma fundamental comum - a crítica da violência -, levaram Benjamin a formulação do paradoxo da relação jurídica: "fins justos, meios legítimos/ meios legítimos, fins justos"Pós-Doutoranda em Filosofia pela Universidade Federal de Santa Catarina, Doutora em Filosofia pela Universidade de São Paulo, Professora de Filosofia e Ciência Politica no Centro Universitário Curitiba, PR. Brasileira, residente em Curitiba-PR. Email: karlapinhelribeiro@gmail.com 
"o paradoxo da insolubilidade de todos os problemas jurídicos", de problematicidade filosófica semelhante na linguagem ao paradoxo do justo e do injusto, do "certo" e do "errado".

À pergunta de Benjamin no ensaio sobre a Crítica da Violência, em oposição ao conceito de violência, partimos de seu pressuposto "criação de direito é criação de poder" para uma resposta crítica ao seu conceito de vida nua que ele mesmo deixou em aberto.

Ao final de sua Crítica da Violência, o ensaio de Walter Benjamin deixa em aberto, a crítica do problema paradoxal e insolúvel das relações jurídicas para a filosofia da história do direito e da justiça que contempla o fundamento do problema crítico da distinção benjaminiana sobre as esferas mítica e divina, que é a questão da origem do dogma da sacralidade da vida. O paradoxo da dissolução da violência jurídica enquanto culpabilidade da vida nua natural que expia o direito.

Essa problematicidade do conceito de vida nua que a Crítica de Benjamin contemplava vem à luz novamente na obra Homo Sacer I de Giorgio Agamben, o conceito de vida nua enquanto fundamento crítico paradoxal da questão da origem do dogma da sacralidade da vida e que segundo pensa Walter Benjamin já ao final de sua Crítica, "o axioma moderno do dogma da sacralidade da vida" faz pensar que "o que aqui é declarado sagrado seja, seguindo ao antigo pensamento mítico, o portador destinado da culpa: a vida nua."

A vida nua do homo sacer é assim, para Walter Benjamin (1996, 251), tal que:

O homem não pode a qualquer preço ser dito coincidir com a vida nua nele nem com a vida nua dele nem pode ser dito coincidir com qualquer outra de suas condições e qualidades de seus estados restantes e propriedades incluindo até a unidade de sua pessoa física.

Chegamos com essa primeira leitura que "com a vida nua cessa o domínio do direito sobre o vivente."

“No sintagma 'vida nua', 'nua' corresponde aqui ao termo haplós, com o qual a filosofia primeira define o ser puro (AGAMBEN, 2002, 187)."

Pós-Doutoranda em Filosofia pela Universidade Federal de Santa Catarina, Doutora em Filosofia pela

Universidade de São Paulo, Professora de Filosofia e Ciência Politica no Centro Universitário Curitiba, PR. Brasileira, residente em Curitiba-PR. Email: karlapinhelribeiro@gmail.com 
O conceito de vida nua para Agamben é interessante, do ponto de vista filosófico da ontologia. A natureza do conceito de vida nua assume uma centralidade para o filósofo uma vez que tem status ontológico originário para o fenômeno do direito na tradição filosófica da história ocidental moderna. O conceito de vida nua pode assim mostrar de que forma e através de que mecanismos jurídicos foi a vida nua incluída/excluída pela máquina jurídica-política moderna e contemporânea.

O que é paradoxal é que mesmo na sua indeterminação e indefinição, pela ausência de uma decifração, é através de uma ontologia que se centre no conceito de vida nua ("que custodia firmemente as chaves do destino histórico-político do ocidente") que poderemos "exprimir a nossa sujeição ao poder político" e através de suas implicações filosóficas teoréticas decifrar o enigma da própria ontologia: "Atingindo o limite do ser puro, a metafísica (o pensamento) transmuta-se em política (em realidade), assim como sobre o limiar da vida nua que a política transgride-se em teoria" (AGAMBEN, 1998, 188).

A questão filosófica contemporânea sobre a ontologia do ser puro e a biopolitização da vida nua atinge um limiar de indistinção. No horizonte da ontologia da biopolítica o pensamento de Giorgio Agamben inicia sobre a linguagem a sua procura da origem do dogma da sacralidade da vida, e encontra, na filosofia da história do direito romano antigo a figura homo sacer.

$\mathrm{Na}$ arqueologia e genealogia do conceito de vida nua na filosofia de Giorgio Agamben encontramos, em seu interior, aquela figura do homo sacer como antiga figura do direito romano arcaico no qual a vida de ser vivo do homem era incluída no ordenamento jurídico romano através de sua exclusão, ou seja, sua matabilidade.

"Vida", no direito romano não era considerada um conceito jurídico, mas indicava o simples fato de viver. O único caso em que o termo "vida" tinha um significado jurídico era no caso do poder do pai sobre a vida e morte dos filhos. É esse o caso que constitui o sentido originário do adjetivo sacer enquanto dispositivo que inclui, através de sua exclusão, a vida humana no direito.

Pós-Doutoranda em Filosofia pela Universidade Federal de Santa Catarina, Doutora em Filosofia pela Universidade de São Paulo, Professora de Filosofia e Ciência Politica no Centro Universitário Curitiba, PR. Brasileira, residente em Curitiba-PR. Email: karlapinhelribeiro@gmail.com 
Assim, a inclusão da vida, no ordenamento jurídico do direito romano antigo através de sua própria exclusão, isto é, de sua própria matabilidade constitui, ainda hoje, na história do mundo em que vivemos, um paradigma jurídico-político do nosso tempo.

Marcel Mauss afirma sobre as diversas noções do sagrado: "Para que a existência de um certo princípio de operações mentais seja clara, é necessário e suficiente que estas operações possam não se explicar por si mesmas. Nós não poderíamos deixar de contestar a universalidade da noção de sagrado e, portanto, não será difícil de citar em sânscrito ou em grego uma palavra que corresponda ao sacer dos latinos. [...] os gregos e os hindus não tinham, eles mesmos, uma consciência bastante justa e forte do sagrado?" (MAUSS, 1968, 21)

No mundo ocidental, a inclusão da vida através de sua exclusão, ou seja, de sua matabilidade, constituiu-se ontologicamente, como fundamento arcano, nos códices jurídico-políticos dos estados-nação modernos, cuja forma estado de exceção é paradigmática ainda nos tempos de hoje.

O status ontológico original da vida nua no interior do fenômeno jurídico do pensamento contemporâneo originou-se segundo Giorgio Agamben, desde o fundamento da passagem da Idade Clássica à Moderna, já teorizado por Foucault e Hannah Arendt, e que sua originalidade se constituiu na ruptura do paradigma políticojurídico da modernidade à Antiguidade até o pensamento contemporâneo.

$\mathrm{Na}$ história da filosofia jurídica contemporânea, o conceito de vida nua, sua ontologia, genealogia e arqueologia, na filosofia de Foucault, em especial sua obra $A$ vontade de Saber. Pois, como escreve Agamben sobre Foucault, no Capítulo 1, intitulado "A politização da vida", na Parte 3, "O campo como paradigma do moderno", na obra Homo sacer l: "a sexualidade, a vida biológica são avatares modernos" para o pensamento do conceito de vida nua.

Homo sacer, esta figura jurídica política antiga é o primeiro registro do conceito de vida nua que documenta a origem do dogma teológico jurídico econômico moral e político, a sacralidade da vida.

Hannah Arendt, em seus estudos sobre os campos de concentração, foi quem, segundo Agamben, primeiro observou a natureza totalitária do campo, que marca no Pós-Doutoranda em Filosofia pela Universidade Federal de Santa Catarina, Doutora em Filosofia pela Universidade de São Paulo, Professora de Filosofia e Ciência Politica no Centro Universitário Curitiba, PR. Brasileira, residente em Curitiba-PR. Email: karlapinhelribeiro@gmail.com 
corpo dos cidadãos e dos homens seu signo, e torna o espaço da política em espaço de vida nua.

Em novembro de 1971, numa discussão com N. Chomsky intitulada "Human Nature: Justice versus Power", Foucault responde à questão da natureza humana. Para Foucault (2003, 90-91):

"Na história do conhecimento, a noção de natureza humana (me) parece ter desempenhado essencialmente o papel de indicador epistemológico para designar certos tipos de discurso em relação ou em oposição à teologia, à biologia ou à história."

Tomando o exemplo da biologia, Foucault $(2003,90)$ diz que:

Alguns conceitos têm uma função de classificação; outros, uma função de diferenciação ou de análise; alguns nos permitem, por exemplo, caracterizar os objetos em tecidos, outros isolam elementos como traços hereditários, ou estabelecem o papel do reflexo. Ao mesmo tempo, há elementos que desempenham um papel no discurso e nas regras internas da prática do raciocínio. Mas existem também noções periféricas através das quais a prática científica se designa ela própria, se distingue das outras práticas, delimita seu domínio de objetos, e define a totalidade de suas tarefas futuras. A noção de vida desempenhou esse papel em biologia durante um dado período.

Sobre a questão da natureza humana, Foucault diz como o conceito preciso de natureza humana pode ser pensado por diferentes graus de elaboração, tal como a noção de vida mais contemporaneamente.

A resposta de Foucault, indo além dos preconceitos de classes sociais, concebe naturezas humanas totalmente diferentes. Para Foucault, o colapso do conceito universal de natureza humana singular pode ser considerado semelhante àquele colapso do conceito de vida contemporâneo.

A partir da observação do conceito de vida para a análise, contudo considerando o saber e a documentação histórica das teorias e práticas dos diferentes graus de elaboração da noção de vida, Foucault retorna à questão da natureza humana sobre horizonte da biopolítica.

Pós-Doutoranda em Filosofia pela Universidade Federal de Santa Catarina, Doutora em Filosofia pela

Universidade de São Paulo, Professora de Filosofia e Ciência Politica no Centro Universitário Curitiba, PR. Brasileira, residente em Curitiba-PR. Email: karlapinhelribeiro@gmail.com 
Em 2002, por sua vez, Giorgio Agamben publica a obra O Aberto onde contempla a questão da "natureza humana" diferentemente. Em uma passagem da obra, escrita mais precisamente ao final do último parágrafo do penúltimo ensaio da obra no capítulo intitulado "Ociosidade", Agamben esboça um conceito de natureza humana "que se tornou perfeitamente inoperante".

E nestes ensaios de Agamben sobre o homem e o conceito de biopolítica na contemporaneidade, o conceito de natureza humana apresenta uma nova definição.

Enunciando em forma de teses os resultados de sua pesquisa sobre o conhecimento do homem, sua arqueologia, genealogia e ontologia, Agamben em seu ensaio intitulado "Antropogênese" faz uma leitura, ainda que provisória, sobre a "máquina antropológica ocidental" e enuncia o os seguintes problemas filosóficos:

1) a antropogênese é uma genealogia do ser humano;

2) a ontologia, genealogia e arqueologia do ser humano;

3) o campo de exceção; a

4) a ontologia do ser humano;

5) a ontologia da biopolítica;

6) a antropologia filosófica.

Estas são as seis teses provisórias de Agamben, e a quinta tese é que literalmente estabelece que: "O conflito político decisivo, que governa qualquer outro conflito, é, em nossa cultura, aquele entre a animalidade e a humanidade do homem. A política ocidental é, pois, co-originariamente biopolítica."

\section{A questão da tradução}

De um comentário da tradução do conceito de Gewalt em português e também em inglês e espanhol, principalmente a partir de intervenções durante o Benjamin Lektüren Zur internacionalen Rezeption, um Simpósio do Arquivo Walter Benjamin da Academia de Artes de Berlim, quando a pesquisadora de traduções da Argentina revelou que a tradução de Héctor Murena foi feita do original alemão. Por um equívoco consta da edição que a tradução foi feita a partir da língua inglesa. A tradução em inglês de Pós-Doutoranda em Filosofia pela Universidade Federal de Santa Catarina, Doutora em Filosofia pela Universidade de São Paulo, Professora de Filosofia e Ciência Politica no Centro Universitário Curitiba, PR. Brasileira, residente em Curitiba-PR. Email: karlapinhelribeiro@gmail.com 
Harvard é mundialmente conhecida. Em português temos pelo menos três traduções. A primeira delas teve a ambiguidade e dificuldade de entendimento do conceito de Gewalt em nossa língua exibido no título: Crítica da violência, crítica do poder. A última tradução foi feita em 2011 no Brasil, traduzida por Ernani Chaves e organizado pela Prof. JeaneMarie Gagnebin.

A compreensão de Walter Benjamin da palavra Gewalt tem pelo menos dois significados em alemão, porém, em português, nós temos palavras diferentes para descrever o que é violência, poder ou poder do estado, direito do estado. Derrida em sua leitura do ensaio de Benjamin, Zur Kritik der Gewalt, não sem razão, muitas vezes confunde, de propósito, os significados da palavra Gewalt, como num sentido de crítica àqueles que pensam que essas esferas são muito separadas: a violência e o direito.

Falar de Benjamin é falar do livro e da leitura e sua importância na civilização da humanidade. O Brasil está vivendo atualmente uma explosão tecnológica digital. Porém, não tivemos a época da literalidade, da leitura como um hábito. Os brasileiros em geral leem menos de um livro por ano. Dentro dessa cultura de iletrismo a filosofia parece ser um terreno infértil, como se houvesse um defeito natural das inteligências brasileiras e que ainda o Brasil não produziu um filósofo ${ }^{3}$ (CRUZ COSTA, 1961, 22). O que temos é comentar e traduzir filósofos estrangeiros, especialmente da Europa, mas como disse Benjamin em Rua de Mão Única, tradução e comentário estão em relação ao estilo e mimese, assim como o som das folhas ressoa a estação do outono - aproximação. E filosofia também não é isso? Os alemães comentam os gregos, os franceses comentam e traduzem os gregos. Comentar e traduzir também são formas de filosofar. A filosofia brasileira tem influência europeia, mas também tem se preocupado com problemas de sua realidade, como favelas, a violência, polícia, pobreza, a iletralidade, cultura e política ${ }^{4}$ (CRUZ COSTA, 1961, 74)

3 "Da Europa, da cultura europeia portuguesa, herdamos língua, costumes, religião, muitos defeitos e algumas virtudes. Herdamos também certa atitude, terra-a-terra, imediatista de considerar a vida, o mundo."

4 "Naturalmente são as correntes da filosofia europeia que ainda exercem aqui a sua influência, mas o seu alcance e significação revelam-se já, em parte, de maneira diferente daquela pela qual se expressavam no passado."

Pós-Doutoranda em Filosofia pela Universidade Federal de Santa Catarina, Doutora em Filosofia pela Universidade de São Paulo, Professora de Filosofia e Ciência Politica no Centro Universitário Curitiba, PR. Brasileira, residente em Curitiba-PR. Email: karlapinhelribeiro@gmail.com 
Walter Benjamin tem uma ampla recepção no campo da arte, da educação e das ciências humanas. Sua obra $A$ obra de arte da era de sua reprodutibilidade técnica é leitura obrigatória. No século XXI, o Brasil se inicia na política de Walter Benjamin, suas teses de história, seu ensaio Crítica da Violência, que tem muito a dizer sobre o mundo em que vivemos. Nós vemos nossas florestas, nossos mares e rios, montanhas, povos, serem destruídos por causa da exploração do capitalismo, de um modo de vida energético petrolífero automobilístico, pedágios, polícias, empresas multinacionais. Um modo de vida global, que não leva em consideração os aspectos locais de uma população, sua história e sua cultura, costumes e crenças.

Depois de seus estudos em Berna, na Suíça, em 1919, Zur Kritik der Gewalt aparece nos anos seguintes à conclusão de seu Doutorado, sobre o conceito de criticismo no romantismo alemão. Curioso, no entanto; encontrar que depois de ter estudado o romantismo alemão seu objeto em seguida tenha sido a violência. Faz-nos pensar que também este caráter engajado da filosofia de Benjamin desde seus primeiros escritos.

Zur Kritik der Gewalt é um importante texto pela liberdade e radicalidade com que trata o assunto. O problema da violência como uma questão filosófica do direito e da justiça, portanto uma questão ética. Diferente de Hannah Arendt que procura investigar a questão da violência sob o ponto de vista da política, Benjamin também traz em seu ensaio o caráter político da violência, mas preocupa-se de forma central com uma questão moral e de justiça. Benjamin se concentra na questão da violência jurídica, a violência do direito enquanto em sua relação com a ética e com a justiça. Ele faz uma crítica da violência do direito quando descreve seu caráter criador e conservador do direito e da justiça.

Em seu ensaio, Benjamin faz a crítica do direito natural e do direito positivo, de base histórica. Também faz a crítica da violência divina e violência mítica, também criadoras e conservadoras do direito. Minha posição é de que Benjamin não faz apologia da violência e que Crítica da Violência em alguns momentos pode ser considerado um texto pacifista ou mesmo, sobre a não violência. Quando ele fala da violência mítica e divina não está as exaltando, mas sim descrevendo sua função e seu poder na sociedade Pós-Doutoranda em Filosofia pela Universidade Federal de Santa Catarina, Doutora em Filosofia pela

Universidade de São Paulo, Professora de Filosofia e Ciência Politica no Centro Universitário Curitiba, PR. Brasileira, residente em Curitiba-PR. Email: karlapinhelribeiro@gmail.com 
humana. No Brasil, a filosofia alemã é amplamente difundida ${ }^{5}$. Walter Benjamin está amparado por essa tradição, tanto que a influência de Crítica da violência parece derivar daquela mesma Resposta à pergunta o que é lluminismo? de Kant. Da influência de Kant também vem uma concepção de direito como coerção, força, violência, poder e autoridade. Walter Benjamin propõe uma questão para a filosofia do direito: o que é Gewalt? É um caráter do direito? E do poder?

Em Hannah Arendt a diferenciação entre poder e violência parece ser bem clara, enquanto que em Benjamin essa separação não está tão clara, como na diferença e definição de violência como poder do estado e como direito do estado, e ainda na condição de lei e justiça. Mas o mais importante é a definição de Benjamin de violência como meio através do qual a humanidade resolve seus problemas. Por que violência? Por que essa escolha? Existem muitos meios para o Estado e o cidadão resolverem seus problemas, mas ambos escolhem a violência. Em seu ensaio $O$ direito de usar a força, publicado em inglês pela Harvard University Press, Selected Writings, vol. I, V, Benjamin retoma a questão sobre o monopólio da violência apenas pelo Estado. Benjamin analisa as proposições de forma lógica e analítica sobre quem tem o direito de usar a força: 0 Estado, o cidadão, nenhum ou ambos. Neste sentido, o discurso de política internacional atual de guerra contra o terrorismo, que sustenta guerras internas e externas, campos como em Guantánamo, ou como na Síria, e sem ir muito longe, o próprio sistema institucional policial-prisional brasileiro. A habilidade para o uso da violência em conflitos de interesse entre estados e cidadãos surge através de decisões humanas.

A recepção de Benjamin no Brasil possui importantes filósofos brasileiros. Por exemplo, a Prof. Olgária Chain Féres Matos, professora do departamento de Filosofia da USP. Seus trabalhos sobre Benjamin incluem estudos em arte, política e humanidades. Em seu livro, Discretas esperanças, uma coletânea de ensaios filosóficos sobre problemas do mundo contemporâneo, encontra-se um ensaio sobre o conceito de Benjamin de capitalismo e fetiche, mas podemos dizer que a filosofia de Benjamin está

5 Para Cruz Costa, o germanismo é considerado uma das últimas influências da Europa na filosofia brasileira.

Pós-Doutoranda em Filosofia pela Universidade Federal de Santa Catarina, Doutora em Filosofia pela Universidade de São Paulo, Professora de Filosofia e Ciência Politica no Centro Universitário Curitiba, PR. Brasileira, residente em Curitiba-PR. Email: karlapinhelribeiro@gmail.com 
presente de forma implícita em todo o livro. Nós temos também a Jean-Marie Gagnebin, que tem orientado trabalhos sobre Walter Benjamin na filosofia, ambas referências bibliográficas da Biblioteca Internacional do Arquivo Walter Benjamin. O pensamento político de Benjamin está começando a ter uma recepção que está sendo desenvolvida nas áreas de direito, filosofia e ciências sociais. Em 1993, pela ocasião do centenário de Walter Benjamin, a Revista da Universidade de São Paulo organizou uma publicação especial, um dossiê com grandes nomes da cultura brasileira, como Sérgio Paulo Rouanet, Haroldo de Campos, Leandro Konder, Jeane-Marie Gagnebin e Professor Gunther Karl Pressler, que fez a bibliografia das obras de Benjamin no Brasil.

Professor Dussel, filósofo argentino e mexicano, fez uma conferência sobre Benjamin em relação com política da liberação, na Espanha, na Universidade de Murcia. Nesta conferência, o filósofo diz que o que Walter Benjamin intuiu em seu tempo, na América Latina desenvolvemos e realizamos suas intuições. Exemplo disso foi sua citação da eleição do Presidente Lula, que veio da classe trabalhadora, Presidente Evo Morales, descendente de indígenas, Presidente Pepe Mujica, no Uruguai, que foi preso e torturado durante a ditadura militar, como também a Presidenta Dilma, e por ser mulher. O filósofo destaca a importância do método de Benjamin do conhecimento, um ponto de vista epistemológico que é uma herança benjaminiana, o ponto de vista do trabalhador, o ponto de vista da mulher, do povo oprimido.

Se a filosofia no Brasil consiste em comentar e traduzir filósofos estrangeiro e nacionais, mas que comentar e traduzir também são formas de filosofar, exemplo disto temos Prof. Dr. Valerio Rohden, que deixou sua contribuição para a filosofia no Brasil com suas traduções das três Críticas de Kant, que dedicou sua vida a traduzir Kant e ao ensino da filosofia. A tradução vem como uma ponte, um portão de entrada, um acesso ao pensamento e à filosofia. Os comentários que o filósofo brasileiro imprimia muitas vezes como notas à tradução, em conversa direta com a ideia original, mostra sua marca da precisão e do rigor conceitual. Este filósofo brasileiro que teve a "paciência do conceito" foi um dos filósofos mais importantes que o Brasil já produziu.

Podemos afirmar que algumas questões como problemas de tradução e compreensão dos conceitos de Gewalt e seus sinônimos e formas de emprego no texto Pós-Doutoranda em Filosofia pela Universidade Federal de Santa Catarina, Doutora em Filosofia pela Universidade de São Paulo, Professora de Filosofia e Ciência Politica no Centro Universitário Curitiba, PR. Brasileira, residente em Curitiba-PR. Email: karlapinhelribeiro@gmail.com 
são: no ensaio Zur Krik der Gewalt, a palavra Gewalt aparece como sinônimo ou referência a Gesetz, que significa direito, lei e taxa, no sentido de imposto, e Recht, no sentido de lei e certo, correto, direito; suas ideias políticas, como a função da violência com base no direito, Gerecht Gewalt, e ainda gewaltsam, que significa pela força. Benjamin também pensa em Das Recht die Gewalt nas mãos de uma pessoa individual, ele fala em Gewaltatigkeit, violência de um Gewaltanwendung do ser mesmo. Gewalt, enquanto palavra que significa poder, força e violência. Crítica do que é a violência criadora de direito rechtserhaltender Gewalt ist. Assim como os pacifistas e ativistas uma crítica de todo o direito de violência Rechts Gewalt. Uma crítica da violência legal e executiva usada com consciência programada. Zur Kritik der Gewalt é antes de tudo, uma crítica à instituição moderna da polícia, ele fala de uma Gewalt zu Rechszwecken, violência para fins de direito e violência da polícia, Polizeigewalt. o direito da polícia. Disso Benjamin conclui que "toda violência é meio para criar o direito ou conservar o direito", meios de violentar, violar, ou ainda, de meios violentos. Walter Benjamin quando fala da manifestação da violência mítica fala também de meio violento e de direito de violência ou violência do direito, Rechtsgewalt. A violência mítica como criadora de direito. Assim como a violência divina exemplificada com a lenda de Niobe, este caráter da violência. Porém a violência mítica e a violência divina como reguladoras das vidas simples, ou vida nua. ${ }^{6}$ Uma ligação direta com a vida dos seres mesmos e suas vontades. Mas ele explica que a violência divina não é a religião nem um pensamento de justiça terrorista. É apenas o direito e a justiça do vir a ser. Benjamin escreve: "A crítica da violência é a filosofia de sua história", mais além da violência política, do militarismo, uma Gestaltungen der Gewalt, violência criadora e conservadora de direito, mas também das relações da violência mítica e divina, violência histórica e a violência natural.

Por outro lado, Walter Benjamin considera que a tarefa de uma crítica da violência

6 Blossen Leben: a tradução é controversa, e já rendeu até teses de doutorado e mestrado no Brasil. Tudo porque o filósofo italiano Giorgio Agamben, tradutor da obra completa de Benjamin em italiano, traduziu o termo Blossen Leben como vida nua, e sobre ele fundou toda sua filosofia. Ele atribui a autoria original do conceito a Benjamin. Ele só desenvolveu sua intuição. Já para Jeane-Marie Gagnebin, a tradução de Giorgio Agamben é equivocada e em alemão este termo não tem esse significado. Para ela, Agamben força demais o conceito.

Pós-Doutoranda em Filosofia pela Universidade Federal de Santa Catarina, Doutora em Filosofia pela Universidade de São Paulo, Professora de Filosofia e Ciência Politica no Centro Universitário Curitiba, PR. Brasileira, residente em Curitiba-PR. Email: karlapinhelribeiro@gmail.com 
se circunscreve às suas relações com o direito e com a justiça. Para ele, uma causa só se transforma em violência quando interfere em questões éticas, as quais são designadas pelos conceitos de direito e justiça. Assim, para Walter Benjamin, a violência só pode ser procurada na esfera dos meios. Sua pergunta consiste em saber se a violência é em determinados casos meio para fins justos ou injustos; e se a violência em geral, enquanto princípio, é ética, mesmo quando meio para fins justos.

Para Walter Benjamin, sem a consideração pelos fins aos quais servem, uma diferenciação na esfera dos próprios meios caracteriza uma grande tendência na filosofia do direito: o direito natural. Segundo sua concepção, a violência é um produto da natureza, tal qual uma matéria-prima cuja utilização não está sujeita a nenhum problema, a não ser que haja abuso da violência para fins injustos. Walter Benjamin considera que toda violência adequada a fins naturais se torna por isso conforme ao direito, um dogma da filosofia do direito. Isto está em oposição ao direito positivo que considera a violência um produto do devir da história. A teoria positiva opera uma diferenciação no conceito de violência enquanto devir histórico, independentemente de sua aplicação: violência sancionada e não sancionada.

Diante disto, Walter Benjamin se interroga sobre a implicação para a essência da violência dessa diferenciação - conforme ao direito e não conforme ao direito. Nas relações jurídicas no que diz respeito aos indivíduos, tende a não se admitir fins naturais alcançados pela violência. Para Benjamin, o direito considera a violência nas mãos dos indivíduos um perigo capaz de solapar o ordenamento do direito. O interesse do direito em monopolizar a violência em relação aos indivíduos não se explicaria pela intenção de garantir os fins do direito, mas sim pela intenção de garantir o próprio direito. Assim, a violência, quando não se encontra nas mãos do direito estabelecido, qualquer que seja, o ameaça de forma perigosa, não em razão dos fins que se quer alcançar, mas por sua simples existência fora do direito.

Na última guerra mundial, a crítica da violência militar tornou-se incipiente para uma apaixonada crítica da violência em geral, que ensinou que a violência não pode mais ser exercida nem tolerada de maneira inocente, transformou-se em objeto de crítica também pela função da violência que é característica do militarismo. "O militarismo é a Pós-Doutoranda em Filosofia pela Universidade Federal de Santa Catarina, Doutora em Filosofia pela Universidade de São Paulo, Professora de Filosofia e Ciência Politica no Centro Universitário Curitiba, PR. Brasileira, residente em Curitiba-PR. Email: karlapinhelribeiro@gmail.com 
imposição do emprego universal da violência como meio para fins de Estado." Nele,

a violência mostra-se numa função completamente diferente daquela de sua simples aplicação para fins naturais. A imposição consiste na aplicação da violência como meio para fins de direito. Pois a subordinação dos cidadãos às leis - no caso, à lei do serviço militar obrigatório - é um fim de direito." (BENJAMIN, 2011, 131-132)

Para Benjamin, se de fato a violência [Gewalt] for a origem do direito, então se pode supor que, no poder [Gewalf] ${ }^{7}$ supremo, o poder sobre a vida e a morte, quando este entra na ordem jurídica dessa ordem, se destaca de maneira representativa no existente e nele se manifesta terrivelmente. Os dois tipos de violência, a que instaura o direito e a que mantém o direito estão presentes na polícia, uma instituição do Estado moderno. A polícia é uma violência para fins de direito (direito de disposição), mas também é competente simultaneamente para ampliar o alcance desses fins de direito (direito de ordenar medidas). A infâmia de tal instituição, segundo Benjamin, consiste no fato de que nela há a suspensão da separação entre a violência que instaura e a violência que mantém o direito. Ela é instauradora do direito, quando de sua função de emitir decretos de todo o tipo, quando o faz com pretensão de direito, e é mantenedora do direito, uma vez que se coloca à disposição de tais fins. Assim, a afirmação de que os fins da violência policial seriam sempre idênticos aos do resto do direito, ou pelo menos teriam relação com estes, é inteiramente falsa. Pelo contrário,

o direito da polícia assinala o ponto em que o Estado, seja por impotência, seja devido a conexões imanentes a qualquer ordem de direito, não consegue mais garantir, por meio dessa ordem, os fins empíricos que ele deseja alcançar a qualquer preço." (BENJAMIN, 2011, 136)

Por esse motivo:

a polícia intervém por 'razões de segurança' em um número incontável de

7 Aqui podemos observar um exemplo da dificuldade de tradução e compreensão do ensaio benjaminiano pela barreira da língua. Entender quando Benjamin está se referindo à violência ou ao direito/poder/autoridade quando usa a palavra alemã Gewalt. As traduções variam muito, tanto em português, espanhol, inglês e italiano. Porém, foi necessário um recurso ao conhecimento histórico e cultural mais profundo da língua alemã para começar a aproximação teórica. Este problema foi também observado por Jacques Derrida, em sua interpretação do ensaio de Benjamin.

Pós-Doutoranda em Filosofia pela Universidade Federal de Santa Catarina, Doutora em Filosofia pela

Universidade de São Paulo, Professora de Filosofia e Ciência Politica no Centro Universitário Curitiba, PR. Brasileira, residente em Curitiba-PR. Email: karlapinhelribeiro@gmail.com 
casos nos quais não há nenhuma situação de direito clara; para não falar nos casos em que sem qualquer relação com fins de direito, ela acompanha o cidadão como uma presença que molesta brutalmente ao longo de uma vida regulamentada por direitos, ou pura e simplesmente o vigia.

Walter Benjamin também se pergunta se não existiriam outros meios, não violentos, para regulamentação dos interesses humanos em conflito. A resposta não resulta em um contrato de direito, pois este, mesmo realizado de maneira pacífica, concede às partes o direito de recorrer à violência uma hora ou outra. É possível a resolução não violenta de conflitos? Não há dúvida. As relações particulares entre as pessoas apresentam muitos exemplos disso. Para Walter Benjamin, existe o acordo não violento onde a cultura do coração concede à humanidade meio para o puro entendimento: cortesia, amor à paz e confiança são seus pressupostos subjetivos.

Em todo campo de forças [Gewalten] levadas em consideração pelo direito natural e pelo direito positivo, não se encontra fuga para o grave problema da violência do direito. Assim, é importante observar que, em uma das traduções utilizadas, a organizadora Jeane Marie Gagnebin nota que Benjamin não escreve um ensaio pacifista, "mas tenta delimitar os vários domínios nos quais Gewalt (a 'violência', o 'poder') se exerce, em particular para refletir sobre a oposição entre o 'poder-como-violência' do direito e do Estado, e a 'violência-como-poder' da greve revolucionária. § O substantivo Gewalt provém do verbo arcaico walten: 'imperar', 'reinar', 'ter poder sobre', hoje empregado quase exclusivamente em contexto religioso. Se o uso primeiro de Gewalt remete a potestas, ao poder político e à dominação - como no substantivo composto Staatsgewalt, 'autoridade ou poder do Estado' -, o emprego da palavra para designar o excesso de força (vis, em latim) que sempre ameaça acompanhar o exercício do poder, a violência, este se firma no uso cotidiano a partir do século XVI (daí, por exemplo, Vergewaltigung, 'estupro'). Por essa razão, Willi Bolle traduziu o título do ensaio 'Zur Kritik der Gewalt' como 'Crítica da violência - Crítica do poder' (em Documentos de cultura, documentos de barbárie: escritos escolhidos) e João Barrento, como 'Para uma crítica do poder como violência' (em Anjo da história). De todo modo, o que importa é ressaltar a dupla acepção do termo Gewalt, que indica, em si mesmo, a imbricação entre poder político e violência Curitiba, PR. Brasileira, residente em Curitiba-PR. Email: karlapinhelribeiro@gmail.com 
que constitui o pano de fundo da reflexão de Benjamin. Cabe observar ainda que, no plural, Gewalten, costuma ser traduzido também por 'forças'". (BENJAMIN, 2011, 121 122)

Jacques Derrida em sua obra intitulada Força de lei, propõe uma hermenêutica do texto de Walter Benjamin, onde ele apresenta a dificuldade em se compreender os problemas apresentados por este texto, como por exemplo, como é possível diferenciar por um lado, uma força que seja justa de uma violência que julgamos injusta e pergunta "o que é uma força justa ou uma força não violenta?" (DERRIDA, 2010, 9) ; bem como, para começar, a dificuldade de se traduzir a palavra alemã Gewalt, que é frequentemente traduzida por "violência", mas que de fato significa também em alemão, "poder legítimo", "autoridade", "força pública".

Gesetzgebende Gewalt é o poder legislativo, geistliche Gewalt é o poder espiritual da Igreja, Staatsgewalt é a autoridade ou o poder do Estado". Gewalt é, portanto, ao mesmo tempo a violência e o poder legítimo, a autoridade justificada. Como distinguir entre a força de lei de um poder legítimo e a violência pretensamente originária que precisou instaurar essa autoridade, e que não podia ela mesma se autorizar por nenhuma legitimidade anterior, de tal forma que ela não é, naquele momento inicial, nem legal nem ilegal, outros diriam apressadamente nem justa nem injusta? (DERRIDA, 2010, 9-10)

Em Força de lei, no capítulo intitulado Do direito à justiça, Jacques Derrida apresenta em sua hermenêutica do texto de Benjamin, uma desconstrução do conceito de justiça, a partir da qual chega a três exemplos de aporias, que são por ele denominadas da seguinte forma: 1) a epokhé da regra; 2) a assombração do indecidível; 3) a urgência que barra o horizonte do saber. Na primeira aporia, encontra-se o argumento de que dizer que algo é justo de acordo com uma regra é uma posição que eclipsou no mundo contemporâneo, onde a compreensão de justiça está mais ligada a um conjunto de elementos materiais, bem como a compreensão de uma decisão. Por sua vez, a segunda aporia apresenta um problema paradoxal para o conceito de decisão, que também apresenta uma situação eclipsada diante daquilo que é inde cidível, bem como a possibilidade de que quando há a garantia dessa tal decisão. A terceira aporia consiste naquela mesma compreensão da filosofia kantiana, e sua questão sobre os limites do conhecimento, como na célebre pergunta constante de sua Lógica: "O que posso saber?", que remete ao domínio da ciência, mas que, como também a moral e a Pós-Doutoranda em Filosofia pela Universidade Federal de Santa Catarina, Doutora em Filosofia pela Universidade de São Paulo, Professora de Filosofia e Ciência Politica no Centro Universitário Curitiba, PR. Brasileira, residente em Curitiba-PR. Email: karlapinhelribeiro@gmail.com 
religião, terminam por fim com a resposta antropológica: "O que é o homem?".

No segundo capítulo de Força de lei, intitulado Prenome de Benjamin, Jacques Derrida comenta o texto de Walter Benjamin Crítica da violência, sob uma perspectiva do nazismo na Alemanha. Para Jacques Derrida, o ensaio Crítica da violência de Walter Benjamin consiste em uma análise de reflexão da crise europeia da democracia liberal, parlamentar burguesa e do conceito de direito a ela inerente. Segundo Derrida, Walter Benjamin queria realmente, com efeito, inaugurar uma "filosofia do direito", portanto, sua questão concerne mesmo, ao direito (Recht). Para isso, Walter Benjamin se muniu de várias diferenciações, segundo Jacques Derrida, todas elas interessantes, necessárias e provocadoras, porém um tanto, ou muito problemáticas. A primeira distinção demonstrada por Walter Benjamin que Jacques Derrida observa é a diferenciação entre as duas violências do direito: a violência instauradora do direito e a violência conservadora do direito. A segunda distinção feita por Walter Benjamin e que Jacques Derrida observa é aquela entre a violência instauradora do direito que se diz "mística" e a violência destruidora do direito que se diz "divina". A terceira distinção operada por Walter Benjamin e que Jacques Derrida observa é aquela entre a justiça, como princípio de toda a colocação divina de finalidade, e o poder, como princípio de toda fundação mística de direito.

Para Derrida, a palavra "crítica" no sentido utilizado por Benjamin não significa de modo simples uma apreciação de forma negativa, ou uma rejeição ou mesmo uma condenação da violência considerada legítima, mas sim uma análise para se julgar a violência e seus meios. Assim, para Jacques Derrida, a concepção de crítica possui uma relação íntima com o conceito de julgamento e com o próprio direito. Segundo o filósofo, a conceituação da violência [Gewalt] para Walter Benjamin só é possível através de sua relação com o direito, com a justiça e com a moral. Deste modo, para eles não há violência física ou natural. Derrida cita o exemplo em que se fala da violência de um terremoto ou mesmo de uma dor física, porém, não se está falando de uma Gewalt a qual pode dar lugar a um julgamento em alguma instância judicial. "O conceito de violência pertence à ordem simbólica do direito, da política e da moral - de todas as formas de autoridade ou de autorização, ou pelo menos de pretensão à autoridade. E é Pós-Doutoranda em Filosofia pela Universidade Federal de Santa Catarina, Doutora em Filosofia pela

Universidade de São Paulo, Professora de Filosofia e Ciência Politica no Centro Universitário Curitiba, PR. Brasileira, residente em Curitiba-PR. Email: karlapinhelribeiro@gmail.com 
somente aí que ele pode dar lugar a uma crítica“ (DERRIDA, 2010, 74-75).

$\mathrm{Na}$ análise de Derrida, a objeção feita por Walter Benjamin de que a violência pode ser vista como meio para fins justos ou injustos impede que a violência seja julgada, ela mesma, como moral, seja qual for o fim a que almeja. Segundo Jacques Derrida, essa objeção foi deixada de fora pela tradição do direito natural, para a qual o uso da violência não apresenta problemas, tendo em consideração que os fins naturais são justos. A partir desse ponto de vista, observa Derrida, a violência é considerada um "produto natural". Por outro lado, embora o direito positivo tenda a considerar o devir histórico do direito e, ele também apresenta uma crença nos meios bons, ou seja, aqueles conforme ao direito. Dessa forma, a tradição juspositivista propõe que sejam julgados os meios em conformidade com o direito que está por vir, e, portanto, não natural. Todavia, embora as duas tradições divirjam quanto à justiça de meios e fins do direito, segundo Derrida ambas arcam juntamente com um dogma comum: fins justos podem ser alcançados por meios injustos.

$\mathrm{Na}$ análise de Derrida, Benjamin pretende exceder a essas duas principais tradições do direito e situar a sua crítica para além do domínio do direito e das instituições jurídicas e busca mesmo uma "filosofia da história", porém limitando-se de forma explícita à prática habitual do sistema jurídico europeu. Jacques Derrida observa o que o direito europeu tem de mais fundamental, ou seja, a proibição da violência individual e sua condenação ao ponto em que ela se torne uma ameaça não somente a uma lei específica, mas a todo o ordenamento jurídico. Provém daí, segundo Derrida, o interesse do direito em se instaurar e se conservar a si mesmo. E interesse é de fato a palavra utilizada por Walter Benjamin.

Falar de um interesse do direito pode parecer 'surpreendente', é a palavra usada por Benjamin; mas é ao mesmo tempo normal, é da natureza de seu próprio interesse pretender excluir as violências individuais que ameaçam sua ordem; é com vistas a seu interesse que ele monopoliza, assim a violência no sentido de Gewalt, a violência enquanto autoridade. Há um 'interesse do direito na monopolização da violência' (Interesse das Rechts an der Monopolisierung der Gewalt). Esse monopólio não tende a proteger determinados fins justos e legais (Rechtszwecke), mas o próprio direito. (DERRIDA, 2010, 77-78)

Pós-Doutoranda em Filosofia pela Universidade Federal de Santa Catarina, Doutora em Filosofia pela Universidade de São Paulo, Professora de Filosofia e Ciência Politica no Centro Universitário Curitiba, PR. Brasileira, residente em Curitiba-PR. Email: karlapinhelribeiro@gmail.com 
De acordo com Derrida, a ordem jurídica revela-se de modo completo na faculdade de pena de morte. Na extinção da pena de morte não se extinguiria um mecanismo qualquer, mas "o próprio princípio do direito. Assim se confirma que há algo de 'podre' no âmago do direito" (DERRIDA, 2010, 97-98). A pena de morte é prova de que "o direito é uma violência contrária à natureza". Misturando as duas formas de violência em Benjamin, a violência que cria e a que conserva o direito, encontra-se a instituição moderna da polícia. Segundo Derrida, em se tentar definir a polícia, nunca se sabe com quem se está tratando, por ser a polícia uma instituição com limites indetermináveis. Para Jacques Derrida $(2010,98)$ :

a polícia moderna é estruturalmente repugnante, imunda por essência, em razão de sua hipocrisia constitutiva. Sua ausência de limite não Ihe vem apenas de uma tecnologia de vigilância e repressão, que já se desenvolvia em 1921 de modo inquietante, a ponto de duplicar e assombrar toda vida pública ou privada (que diríamos nós, hoje, do desenvolvimento dessa tecnologia!)

Por fim, Derrida observa a constatação benjaminiana de que o direito é inseparável da violência, tanto em sua origem quanto em seu fim, tanto em sua fundação quanto em sua conservação e comenta a pergunta de Benjamin que é a interrogação se é possível solucionar conflitos humanos de forma não violenta, e a resposta é obviamente que sim. Os exemplos citados por Derrida são aqueles exemplificados por Benjamin, os existentes nas relações entre pessoas privadas. "Uma união sem violência (gewaltose Einigung) é possível em toda parte onde a cultura do coração (die Kultur der Herzens) dá aos homens meios puros visando a um acordo (Übereinkunft)

\section{CONCLUSÃO}

Nossa pesquisa encontra pontos de diferenças e semelhanças da filosofia Walter Benjamin especificamente no que consiste em suas concepções de direito e de violência. Como vimos, não existe, todavia, uma resposta simplista para suas diferenças e, no entanto, também não possuem uma resposta simples para seus pontos de semelhança. A complexidade do pensamento de Benjamin exige, a seu modo, uma exegese Curitiba, PR. Brasileira, residente em Curitiba-PR. Email: karlapinhelribeiro@gmail.com 
cuidadosa de seus argumentos e proposições. Procuramos escolher algumas questões relativas ao direito e a violência para analisar conjuntamente na obra de Benjamin.

Um ponto em comum entre estes conceitos que encontramos é a obra de Giorgio Agamben, que analisa a filosofia de Benjamin e tenta compor uma filosofia própria. Giorgio Agamben se refere sempre em suas obras que Walter Benjamin é decisivo em seu argumento. Na obra Estado de Exceção, por exemplo, ele se refere à violência, violência que vem sendo justificada e reproduzida em um sistema legal e político que se apresenta como condição indispensável para uma ordem mínima requerida pela vida para ser vivida. Segundo Samuel Webber $(2008,195)$, Benjamin desenvolve uma noção de violência radicalmente distinta do direito (recht, droit, law), que é definido por Benjamin, segundo Webber, como "meio puro", isto é, como uma "medialidade sem fim", que não serve a nenhum propósito e que, portanto, deve ser considerada independente dos fins que persegue. O conceito de pureza para Benjamin, segundo Webber (2008, 196) foi expresso por Agamben, que cita a passagem de uma carta escrita por Walter Benjamin a Ernest Schoen em 1919, onde ele argumenta que a noção de pureza (Reinheit) é mais condicional, do que absoluta.

A pureza de um ser nunca é incondicional ou absoluta; está sempre sujeita a uma condição. Esta condição sempre difere do ser em questão: nunca todavia esta condição reside no ser ele mesmo. Em outras palavras: a pureza de cada ser (finito) não depende dele mesmo (ist nicht von ihm selbst abhängig). Os dois seres aos quais nós atribuímos pureza acima de todos são a natureza e as crianças. (AGAMBEN, 2004, 83-98)

Ser finito, de acordo com Benjamin, é depender de algo que é outro, e não ele mesmo, é situar-se em estranhas condições. Pureza não é uma característica imanente, nem uma propriedade além e aquém de si mesma, como notam Agamben e Webber, é uma característica relacional. No caso da violência, a pureza deve ser procurada não na violência mesma, mas nas suas relações externas. Qualquer coisa que se define e se identifica em termos de sua relação com outra coisa, pode ser considerada em relação a essa outra coisa como sendo um "meio". Mas, em Crítica da violência, Benjamin explicitamente exclui esta concepção teleológica tradicional. A leitura que Webber faz do ensaio benjaminiano inclui sua relação com a biopolítica, que pode ser definida como a

Pós-Doutoranda em Filosofia pela Universidade Federal de Santa Catarina, Doutora em Filosofia pela Universidade de São Paulo, Professora de Filosofia e Ciência Politica no Centro Universitário Curitiba, PR. Brasileira, residente em Curitiba-PR. Email: karlapinhelribeiro@gmail.com 
politização da vida, ou seja, a inscrição da vida natural nos cálculos e estratégias do sistema político (da política); a instrumentalização da vida, desde o dia em que se nasce, ao instante em que se começa a morrer.

Se de acordo com a argumentação que fundamenta a teoria da ética e da justiça é a verdade, o mesmo argumento poderia se inferir ao direito e à política. Para o direito, entendido como ação humana que busca o que é justo, o que é legal, no caso de países de direito positivado, mas também se aplica aos casos de direito de países com direito jurisprudencial. Se o critério que fundamenta o direito é a violência, para ser direito, a ação tem que ser uma ação violenta. Pois é isto que caracteriza uma ação jurídica em Benjamin, sua essência é a violência. Não parece então ser desprovido de propósito o fato de que Giorgio Agamben tenha se espantado tanto com o ensaio benjaminiano sobre a Crítica da violência, como também Derrida o fez e tantos outros, porque a tese que está diante de nós nesse texto, é, se não uma premonição, e daí talvez a celebração de Benjamin como um profeta, um profeta do século XX, e testemunhou sua profecia em carne e osso. A tese do direito nazista é contemplada pelo filósofo e vem por sua vez, também uma outra indicação da razão pelo qual o ensaio provoca no leitor, provocou em Agamben, em Derrida, em Samuel Webber, que esta concepção do direito exposta na Crítica é a mesma proposição que é compartilhada por Carl Schmitt, a quem a autoria intelectual do direito nazista é atribuída. Ensaio que silenciou a leitora Hannah Arendt, que não publicou este texto em sua edição da obra de Benjamin, intitulada em inglês Illuminations. Um dos motivos que levaram Arendt a deixar de fora este texto quando da época da referida publicação, talvez seja este: o pensamento no fato de que o fundamento do direito, assim como a ética e a justiça seja a verdade, o bem e o correto. Fazer o bem, agir corretamente segundo a visão de Hannah Arendt parece também se aplicar ao direito e à justiça. Mas para Benjamin, todavia o que a leitura da Crítica sugere, é que o verdadeiro fundamento do direito é a violência. E para isso, para responder a essa dúvida que perpassa e persiste entre os dois autores, o fundamento crítico do direito, acaba nos levando então inevitavelmente à pergunta feita por Kant, ainda no século XVIII, o que é a verdade?

Segundo Sammuel Webber, para o Benjamin de Crítica da violência, é fácil Pós-Doutoranda em Filosofia pela Universidade Federal de Santa Catarina, Doutora em Filosofia pela Universidade de São Paulo, Professora de Filosofia e Ciência Politica no Centro Universitário Curitiba, PR. Brasileira, residente em Curitiba-PR. Email: karlapinhelribeiro@gmail.com 
identificar o fim de que se deve excluir no sentido de chegar a uma crítica da violência, ou seja, de suas condições de possibilidade e impossibilidade: e este fim é o direito (Recht), isto é "right" e "Law", que significa o âmbito do direito positivo e o domínio da legalidade. A crítica da violência como meio. Mas ao mesmo tempo, o domínio da legalidade aplicada à economia, à política, à ciência e à religião.

Procurar no lugar do pensamento hoje, como sugere incisivamente Giorgio Agamben em Homo sacer, o nómos da terra, bia e diké, a história da justiça e do direito, a lei da terra. Sua origem histórica e cultural no mundo religioso e na modernidade, configurada como momento histórico, no tempo da história que tem como característica fundamental a ruptura do direito com a religião, a justiça agora não emana mais dos deuses, mas é originária dos homens. São eles seus criadores e a partir de agora suas decisões têm autoridade e força de lei. Mas é muito mais difícil descrever em termos positivos as consequências da violência, ou ainda, a condição da violência como um meio sem fim, isto é, um meio puro.

\section{REFERÊNCIAS}

AGAMBEN, G. Homo Sacer I: O Poder Soberano e a Vida Nua. Belo Horizonte: UFMG, 2002. Tradução Henrique Burigo.

AGAMBEN, G. Homo Sacer I: Sovereign Power and Bare Life. Meridian: Crossing Aesthetics. Stanford, Califórnia: Stanford University Press, 1998. Tradução Daniel Heller-Roazen.

AGAMBEN, G. Estado de exceção. São Paulo: Boitempo Editorial, 2004. Tradução Iraci D. Poleti.

ARENDT, H. On violence. New York: Harcourt, 1970.

BENJAMIN, W. Gesammelten Schriften. 17 Band. Frankfurt am Main: Suhrkamp Verlag, 1991.

BENJAMIN, W. Walter Benjamin: Selected Writings, Volume 1, 1913-1926 (ed. Marcus Bullok and Michael Jennings). Cambridge, MA: Belknap Press, Harvard University, 1996.

Pós-Doutoranda em Filosofia pela Universidade Federal de Santa Catarina, Doutora em Filosofia pela Universidade de São Paulo, Professora de Filosofia e Ciência Politica no Centro Universitário Curitiba, PR. Brasileira, residente em Curitiba-PR. Email: karlapinhelribeiro@gmail.com 
BENJAMIN, W. Para uma crítica da violência. In _ : Escritos sobre mito e linguagem. Edição de Jeane-Marie Gagnebin. São Paulo: Editora 34, 2011. Tradução de Ernani Chaves e Susana Kampff Lages.

CRUZ Costa. Panorama da História da Filosofia no Brasil. São Paulo: Cultrix, 1961

DERRIDA, Jacques. Força de lei: o fundamento místico da autoridade. São Paulo: Ed. Martins Fontes, 2010. Tradução de Leyla Perrone-Moisés.

FOUCAULT, Michel. Ditos e Escritos, Vol. IV. Rio de Janeiro: Forense Universitária, 2003. Tradução Vera Lúcia Avellar Ribeiro.

MAUSS, Marcel. Oeuvres 1: Les fonctions sociales du sacré. Paris: Les Éditions de Minuit, 1968.

WEBBER, Samuel. Benjamin's abilities. Cambridge, MA: Harvard University Press, 2008. 